\title{
Heat Energy Recovery System
}

\author{
Ujjawal Kohli*, Vaibhav Mishra, and Sparsh Singh Kotwal \\ Department of Mechanical Engineering, Graphic Era University, Dehradun-248002, INDIA
}

Received January 22, 2018; Accepted March 26, 2018; Published April 27, 2018

\begin{abstract}
Energy demands in today's world have increased and the main area of concerns is that approximately $90 \%$ of world's oil reserves are expected to be depleted within two generations. We are trying to build a technological system where the by-product of conventional fuel i.e., exhaust heat of fuel, will be converted into another form so that it can further be used again. Mainly, recovery of heat energy is our prime motive. According to our motive, we are going to recover the heat of the hot exhaust gases from chimneys of factories which usually dissipate into the atmosphere and thus that exhaust heat left unused. So, we are making a water storing tank i.e., water jacket that will surround the chimney through which heat from hot exhaust gases will come in contact with water present in water jacket. Through the process of conduction, heat transfer will take place. Therefore, due to heat, the temperature of the water will increase to a very high extent, and hot water can be used in boilers as a pre-heater for household or commercial purposes. Furthermore, global warming will also be controlled if we start implementing this technology at a huge scale.
\end{abstract}

Keywords: Chimneys; Conduction; Exhaust; Heat Recovery; Temperature; Water Jacket

\section{Introduction}

The majority of energy production from conventional and renewable resources is lost to the atmosphere due to onsite (equipment inefficiency and losses due to waste heat) and offsite (cable and transformers losses), which sums to be around $66 \%$ loss in electricity value [1-2]. The waste heat of different degrees could be found in final products of a certain process or as a by-product of industry such as from the exhaust producing from steel-making, glass making factories, etc. (Table 1). Heat is that amount of energy flowing from one body to another spontaneously due to their temperature difference or by means other than work or transfer of matter. Heat energy flows from an object of high temperature to an object with a lower temperature. It will never do the reverse until and unless any external force is applied.

In this project, we concentrated an approach towards the recovery i.e., Recovery of waste heat. Approximately, there is a $30-50 \%$ heat energy loss in the form of heat dissipation i.e., by cooling system and exhaust systems. This lost heat may contain heat energy and kinetic energy, which could be further employed for some applications. Extraction of heat energy is a somewhat easy process but recovering energy from an existing system to an extent that it can be used for useful work is difficult. Energy demands are increasing day by day and need a strong solution. No one thought over it for

*Corresponding author: kohliujjawa196@geu.ac.in, vaibhavmishra720@geu.ac.in, sparshkotwal@gmail.com 
many years. So here we are introducing our Heat Energy Recovery System, which will use exhaust gases from chimneys of factories and use this waste energy again in another form. Our project is designed in such a way that it is durable and efficient with very low service requirement [3].

\section{Concept of Waste Heat Recovery}

Waste Heat Recovery means to utilize the heat energy in a better desired way which is expelled or exhausted to the atmosphere. This wasted heat energy can be recovered by coupling some secondary auxiliaries such as water jacket in electric chimneys to extract heat from exhaust gases generated by industries. This reduces wastage and improves efficient utilization of fuel i.e., resources. The lost heat may be utilized for further energy requirements.

Table 1. Waste Exhaust Heat of Various Furnaces

\begin{tabular}{|l|c|}
\hline \multicolumn{1}{|c|}{ Types of Device } & Temperature, ${ }^{\circ} \mathbf{C}$ \\
\hline Nickel Refining furnace & $1370-1650$ \\
\hline Aluminum Refining Furnace & $650-760$ \\
\hline Zinc Refining Furnace & $760-1100$ \\
\hline Copper Refining Furnace & $760-815$ \\
\hline Steel Refining Furnace & $925-1050$ \\
\hline Copper Reverberatory Furnace & $900-1100$ \\
\hline Open Hearth Furnace & $650-700$ \\
\hline Cement Kiln (Dry process) & $620-730$ \\
\hline Glass Melting Furnace & $1000-1550$ \\
\hline Hydrogen plants & $650-1000$ \\
\hline Solid Waste Incinerators & $650-1000$ \\
\hline Fume Incinerators & $650-1450$ \\
\hline
\end{tabular}

\section{Objective}

According to the United States Department of Energy, up to 50 percent of the energy from all fuels burned in the U.S. ends up in the atmosphere as waste heat. Research indicates that recovery of the waste energy from industrial facilities could fulfill up to 20 percent of total domestic electricity demand and simultaneously effect a 20 percent reduction in greenhouse gas emissions. Waste heat is a heat which is generated by a way of fuel combustion or chemical reaction and then dumped into the environment, even though it could still be reused for some useful and economic purpose. A large amount of hot flue gases is generated from boilers, glass factory, sugar factory, furnaces etc. The energy lost in waste gases cannot be fully recovered. If some of this waste heat could be recovered, a considerable amount of primary fuel could be saved [4]. Imagine if this waste heat can be recovered and adopted successfully there will be a revolutionary change in the world in terms of energy reusability. However, as per our analysis, much of the heat could be recovered and losses are minimized. So, the objective of our project is to establish a system which is strong enough to tackle present issues on a recovery of heat energy and efficient enough to make all facts into fiction. 


\section{Material Required}

1. Water tank (at inlet and outlet)

2. Water jacket (around the chimney)

3. Motor

4. Piping system

\section{Construction}

A schematic is designed to understand it in a better way (Fig. 1). Brick and cement made chimneys have low conduction ability. These materials nowadays have become obsolete and are no longer used for making chimneys. Modern chimneys are too way different from old chimneys. Water tank surrounds the chimney up to $80 \%$ of its height. High output is achieved at the storing end. This design is based on modern chimneys, which are now used everywhere and are called as "Electric Chimneys". Electric chimneys are the chimneys which are held high in length, can work up to 24 hours, and it is best suited for our project to provide the output as per we planned [5].

The following standards and assumptions were taken to complete our research.

1. Thermal conductivity of chimney $=379 \mathrm{~W} / \mathrm{m} \mathrm{K}$

2. Thickness of chimney $=0.25 \mathrm{~m}$

3. Inlet exhaust gas temperature $=70^{\circ} \mathrm{C}$

4. Temperature of water before process $=20^{\circ} \mathrm{C}$

5. Mass flow rate $=1 \mathrm{~kg} / \mathrm{s}$

6. Specific heat at constant pressure $=4.180 \mathrm{KJ} / \mathrm{Kg} \cdot \mathrm{K}$

7. Density of air $=2.017 \mathrm{~kg} / \mathrm{m}^{3}$

8. Velocity of inside air $=1 \mathrm{~m} / \mathrm{s}$

9. Height of chimney $=6 \mathrm{~m}$

10. Dynamic viscosity of air $=0.0000182 \mathrm{~m}^{2} / \mathrm{s}$.

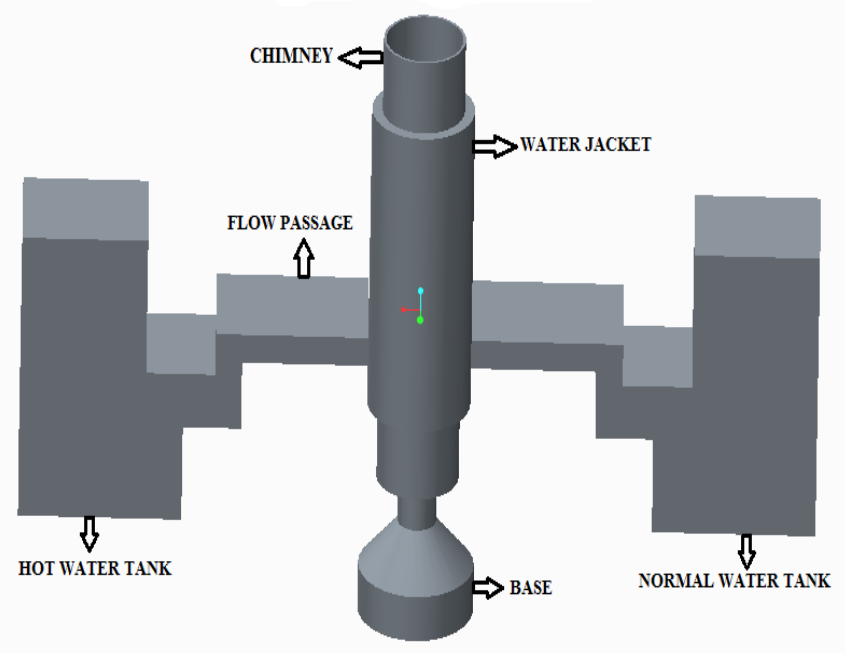

Fig. 1. Schematic of Actual Model 


\section{Code Methodology}

In this project, we use ' $\mathrm{C}$ ' program to create our code. We made our code to calculate the desired output temperature at the water jacket. Standards values are kept in mind while defining the code. All the standards are pre-defined and the actual output is obtained (Fig. 2). Following is the code used in our project.

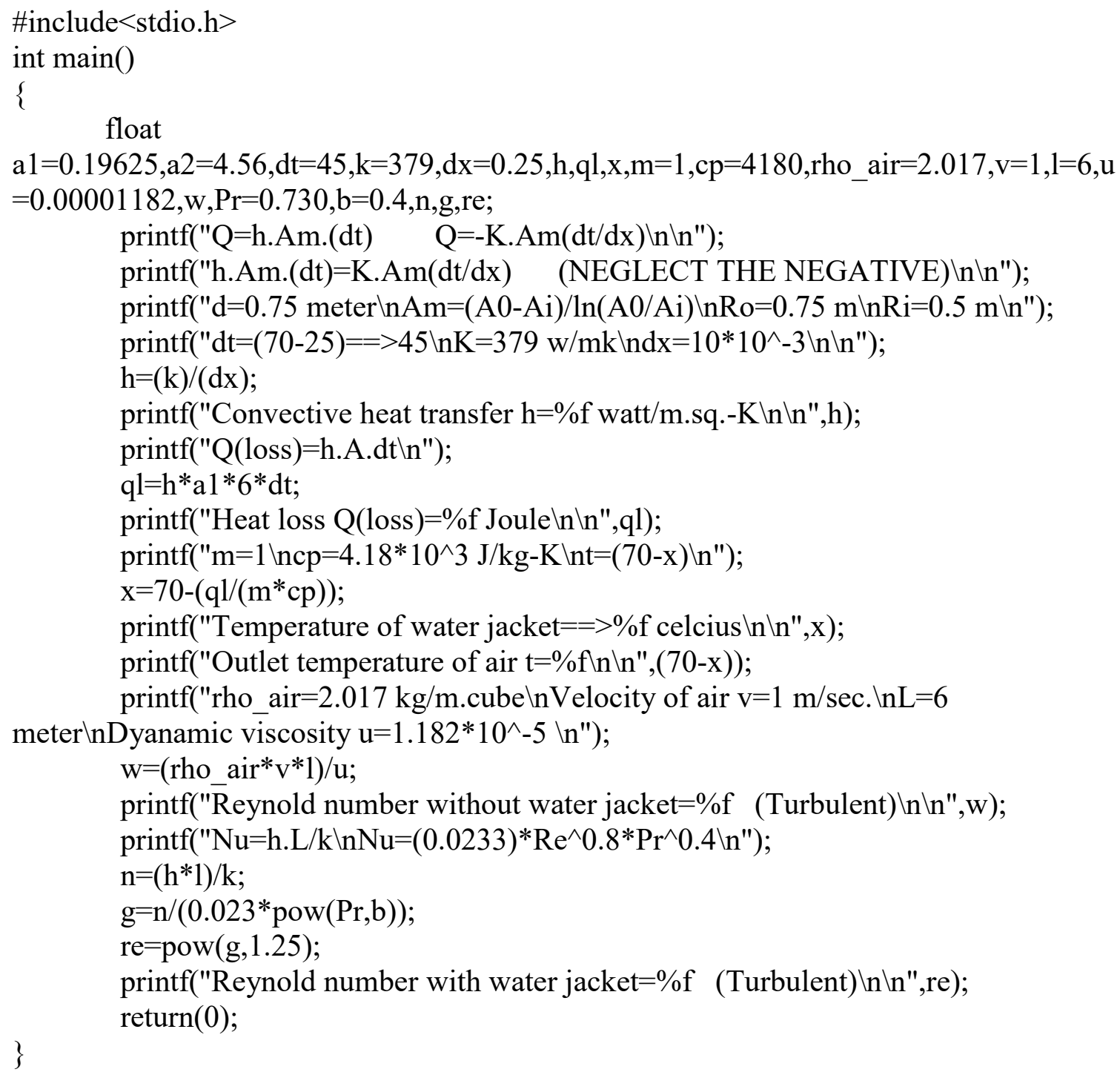

float 


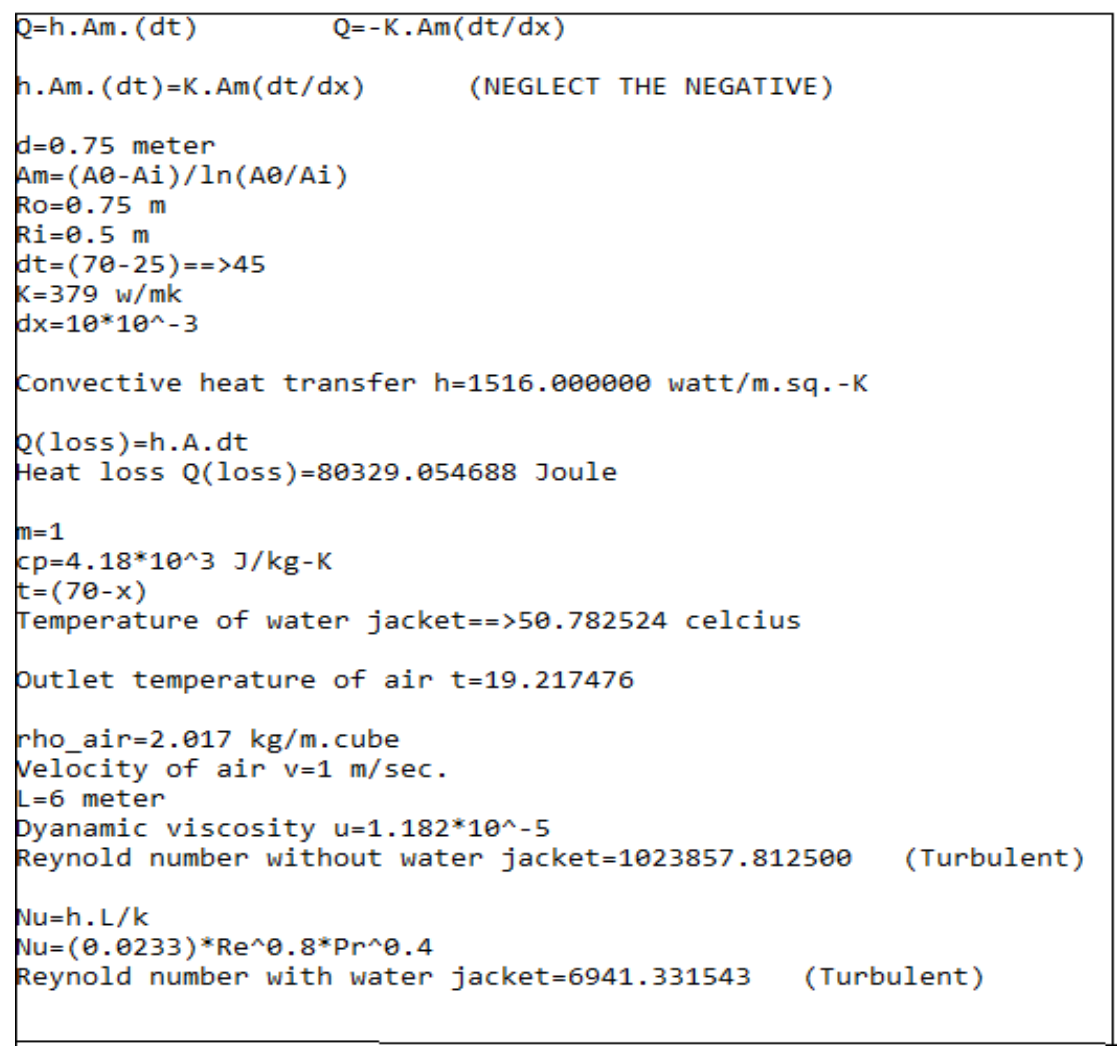

Fig. 2. Output of code

\section{Working}

The working of our project is very simple, i.e., various factories such as glass factory, boilers, sugar factory, furnaces, etc. produce flue gases into the atmosphere through chimneys. So, we are setting up a water jacket surrounding the chimney which will be full of water. After setting up, the waste exhaust flue gases are made to flow through the heat exchanger unit. The temperature of flue gases at the exhaust is initially very high. Due to the flow of hot gases through a heat exchanger, there is an increase in temperature of water which is circulated from feed pump via the heat exchanger to water jacket. Water gets heated and gains temperature through conduction from hot exhaust gases, i.e., waste heat is recovered and the flue gases are exhausted at reduced temperature [6-8]. The temperature of exhaust gases is considerably reduced; this also helps to control global warming. Due to recovery of energy, there will be a considerable reduction in fuel (such as CNG, LPG and other primary fuels) required to heat the water. Also, after that lukewarm or somewhat hot water is transferred to tank through motor which is transferred to household and commercial applications. It can also be used in boilers to work as a pre-heater in household, where it can be used for various purposes such as bathing, washing utensils and clothes, etc.

\section{Applications}


1. Waste heat of medium $\left(120-650{ }^{\circ} \mathrm{C}\right)$ and high $\left(>650^{\circ} \mathrm{C}\right)$ temperature could be used for the generation of electricity or mechanical work via different capturing processes [9-11].

2. Waste heat recovery system can also be used to fulfill refrigeration requirements of a trailer (for example): The configuration is easy as only a waste heat recovery boiler with absorption cooler is required. Furthermore, only low pressures and temperatures needed to be handled.

3. Hot water can also be used for medical purposes such as sterilization of medical equipment. It can be used in household for washing clothes and bathing, and commercially it can be used in the same factories as a pre-heater which will also help in increasing its efficiency [12].

4. Usage of primary fuels will be reduced over a large extent.

5. Due to reduced exhaust gas temperature, it helps in lowering global warming.

\section{Results Obtained}

The proposed design of a plant layout has been analyzed. It's identified that the potential in cement, glass and automobile factories for generation of exhaust heat is the maximum.

As per calculations and research conducted, only reference standard values of all the materials are used as a sample and following results are obtained.

1. Temperature of water before entering in the water jacket $=\mathbf{2 5}^{\circ} \mathbf{C}$.

2. Minimum temperature of exhaust gases entering in the chimney $=\mathbf{7 0}^{\circ} \mathbf{C}$.

3. Rise in temperature exhaust gas comes in contact with water jacket $=\mathbf{5 0}^{\circ} \mathbf{C}$

4. Reynolds's number for exhaust gases without using water jacket comes out to be $=10238.812500$. [TURBULENT FLOW]

5. Reynolds's number for exhaust gases when the water jacket is used, comes out to be $=6941.331543$. [TURBULENT FLOW]

NOTE: Value of Reynolds's number remains turbulent even when heat is extracted from exhaust gases by using a water jacket. Waste heat is successfully recovered, and our prime motto is achieved. Also, due to success of this research, various global warming gases will be greatly reduced.

\section{Conclusion and Future Scope}

The waste heat energy of flue gases through chimney is recovered. This recovered heat can be utilized to generate i.e., to heat the water and this water can be further used for pretreatment and conservation of various processes. Heat exchanger acts as a basic recovery device. In this application, there is an efficient utilization of heat i.e., heat recovery. The approach of review of this research is towards the heat recovery technique and simple implementation for various systems in day to day life. These techniques have proven better, beneficial and eco-friendly. It is also a way and hope of energy saving. 


\section{CONFLICTS OF INTEREST}

The authors declare that there is no conflict of interests regarding the publication of this paper.

\section{REFERENCES}

[1] S. S. Thakare and J. A. Hole, "Review of analysis of heat recovery from top coat oven in paint shop", International Journal of Engineering Research and Technology, vol. 4, no. 2, pp.1085-1088, 2015.

[2] R. Soltani, I. Dincer and M. A. Rosen, "Thermodynamic analysis of a novel multigeneration energy system based on heat recovery from a biomass CHP cycle", Appl. Thermal Engineering, vol 89, pp.90-100, 2015.

[3] T. S. Jadhav and M. M. Lele, "A case study on energy saving in air conditioning system by heat recovery using heat pipe heat exchanger", International Journal of Engineering Research and Technology, vol. 3, no. 2, pp. 12-16, January 2014.

[4] G. V. Pradeep Varma and T. Srinivas: "Design and analysis of a cogeneration plant using heat recovery of cement factory", Case studies in Therm. Eng., vol. 5, pp. 2431, 2015.

[5] R. Saidur, W. K. Muzammil, S. Paria, M.H. Hassan, M. Rezaei and M. Hasanuzzaman, "Technologies to recover heat from internal combustion engines" Renewable and Sustainable energy reviews, vol. 16, pp.5649-5659, 2012.

[6] F. Pask, J. Sadhukhan, P. Lake, S. McKenna, E.B. Perez and A. Yang: "Systematic approach to industrial oven optimization for energy saving", Appl. Therm. Eng., vol. 71, no. 1, pp.72-77, 2014.

[7] P. Ahmadi, M. A. Rose and I. Dincer: "Themodynamicmodeling and multiobjective evolutionary-based optimization of new multigeneration energy system", Energy Conver. Manag., vol. 76, pp. 282-300, 2013.

[8] T.A.H. Ratlamwala, M. A. Gadalla and I. Dincer: "Performance analysis of a novel integrated geothermal-based system for multi generation applications", Appl. Thermal Eng., vol. 40, pp. 71-79, 2012.

[9] S. B. Riffat and A. Mardiana-Idayu, "Review on heat recovery technologies for building applications", Renewable and Sustainable Energy Reviews, vol. 16 pp. 1241-1255, 2012.

[10] M. Ahamadzadehtlatapeh and Yau Y.H., "Predicting yearly energy recovery and dehumidification enhancement with a heat pipe heat exchanger using typical meteorological year data in tropics", Journal of Mechanical Science and Technology, vol. 25, no.4, pp. 847-853, 2011.

[11] N.A. Madloola, N.A. Rahim, M.S. Hossiana and R. Saidutra: "A critical review on energy use and saving in cement industries", Renewable and Sust. Energy Rev., vol. 15, pp. 2042-2060, 2011.

[12] E. Wang, M. Ouyang, X. Li, J. Li and S. Xia, "Control system design for variable nozzle turbocharger", SAE (Society of Mechanical Engineers) paper no. 2009-011668. Presented at non-conference specific technical papers-2009, July 2010. Warrendale, PA, USA 
Article copyright: (C) 2018 Ujjawal Kohli, Vaibhav Mishra and Sparsh Singh Kotwal. This is an open access article distributed under the terms of the Creative Commons Attribution 4.0 International License, which permits unrestricted use and distribution provided the original author and source are credited. 